\title{
Extracardiac conduit in total cavopulmonary connection
}

\author{
Conduto extracardíaco na derivação cavopulmonar total
}

Paulo Paredes PAULISTA, Luiz Carlos Bento de SOUZA, Paulo CHACCUR, Mário ISSA, Antonio Flávio Sanches de ALMEIDA, Ana Luiza Paulista GUERRA, Renato Tambellini ARNONI, Paulo Henrique Dagola PAULISTA, Maria Virginia Tavares SANTANA

RBCCV 44205-638

\section{Abstract}

Objective: This study evaluates a new technique of an extracardiac conduit in total cavopulmonary connection in complex congenital heart disease.

Methods: Between May 2000 and October 2002, 18 extracardiac conduit surgeries were performed. The patients' weights ranged from 11 to 29 kilograms, the ages ranged from 1 to 12 years old and 10 patients were male. There were eight patients with tricuspid atresia, eight with univentricular heart, and two with unbalanced total atrioventricular septal defect. There were 17 patients who had been submitted to a previous palliative surgery. The surgery was performed at over $32^{\circ}$ centigrade without aortic ischemia. Ten PTFE, 4 Hemashield and 4 bovine pericardium tubes were used with diameters ranging from 16 to $22 \mathrm{~mm}$.

Results: There were four cases of tube thrombosis and these patients were a reoperation was performed with one death. In one patient a takedown was performed on the $69^{\text {th }}$ postoperative day. There were three deaths, one due to tube thrombosis and two due to low cardiac output.

Conclusion: Extracardiac conduit is already used for total cavopulmonary connection, but despite encouraging early results, a longer follow-up is necessary to prove its real advantages.

Descriptors: Heart bypass, right. Pulmonary artery, surgery. Heart defects, congenital, surgery.

Work performed in the Dante Pazzanese Institute of Cardiology, São Paulo, SP

Correspondence address: Dr. Paulo Paredes Paulista. Av. Dante Pazzanese, $500-11^{\circ}$ andar. São Paulo, SP, Brazil. CEP 04012-180. Phone: (11) 5085-4034. Fax: (11) 5549-1101.

E-mail: paulistapaulo@ig.com.br

Article received on April, 2003 Article accepted on September, 2003 


\author{
Resumo: \\ Objetivo: Avaliar a utilização de conduto extracardíaco na \\ confecção de derivação cavopulmonar total nos diferentes \\ tipos de cardiopatias complexas nas quais está indicado este \\ tipo de correção. \\ Método: Entre maio de 2000 e janeiro de 2003, foram \\ operados 18 pacientes, 10 do sexo masculino, com idades entre \\ 1 e 12 anos e peso variando de 11 a 29 quilos. O diagnóstico \\ principal foi atresia tricúspide em oito pacientes, conexão \\ atrioventricular univentricular em oito e defeito total do septo \\ atrioventricular desbalanceado em dois. Apenas um paciente \\ foi operado sem cirurgia paliativa prévia. A operação foi \\ realizada com emprego de circulação extracorpórea com \\ temperatura acima de $32^{\circ} \mathrm{C}$ orofaríngea e sem isquemia \\ aórtica. Foram empregados, entre a veia cava inferior e a
}

\section{INTRODUCTION}

FONTAN \& BAUDET [1] first established the concept of a non-anatomic correction of a case of tricuspid atresia, where the venous blood was directed to the lungs without passing through the right ventricular chamber. This approach then had its indications amplified and underwent a series of modifications. These modifications started with atriopulmonary connections and continued to more rational alternatives, where the superior and inferior vena cavas were connected to the pulmonary circulation without passing through the right atrium.

This type of intervention, initially called total cavopulmonary connection by KAWASHIMA et al. [2], in reality was not total, as it allowed the venous blood from the supra-hepatic veins to circulate through the lungs. This operation was a bi-directional Glenn-type anastomosis (superior vena cava-right pulmonary artery) in a case of agenesis of the intra-hepatic portion of the inferior vena cava, which drained to the superior vena cava by the azygos system.

The total cavopulmonary connection was first published by PUGA et al. [3], but JONAS \& CASTANEDA [4] and DE LEVAL et al. [5] soon followed their example. The latter authors highlighted the advantages of directing the blood from the inferior vena cava to the right pulmonary artery by means of a tunnel. In this way the fluid dynamics of the blood is preserved and the venous pressure of the rest of the right atrium is relieved, with positive gains in relation to reducing post-operative arrhythmias. To achieve this, however, many intra-atrium sutures are required which eventually can provoke the same arrhythmias. For this, an extracardiac conduit was used to perform the connection between the inferior vena cava and the pulmonary circulation, which is simpler and avoids atrial sutures, and it was soon recognized as the best option.

The aim of this work is to assess the experience of the circulação pulmonar, 10 tubos de PTFE, quatro de Hemashield e quatro de pericárdio bovino, com números variando de 16 a $22 \mathrm{~mm}$ de diâmetro.

Resultados Ocorreram quatro casos de trombose no tubo, todos reoperados, com um óbito. Em um paciente, após 69 dias da operação, foi realizado "takedown" para Glenn bidirecional. Entre os 18 pacientes ocorreram três óbitos, um por trombose do tubo e dois por síndrome de baixo débito no pós-operatório imediato.

Conclusão: $\mathbf{O}$ emprego de tubo extracardíaco já faz parte da técnica de derivação cavopulmonar total, mas sua indicação merece cuidados especiais.

Descritores: Derivação cardíaca direita. Cardiopatias congênitas, cirurgia. Técnica de Fontan.

Dante Pazzanese Institute of Cardiology using this procedure.

\section{METHOD}

Between May 2000 and January 2003, 18 consecutive patients with heart disease and indications for total cavopulmonary connections were operated on using the extracardiac conduit procedure to make the connection between the inferior vena cava and the pulmonary circulation.

The ages of these patients ranged from 1 to 12 years with an average of 4.3 years and their weights varied from 11 to 29 kilograms with a mean of 14.9 kilograms. Ten patients were male and eight female.

The principal diagnoses of these 18 patients were tricuspid atresia in eight, univentricular atrioventricular connection in eight and unbalanced total atrioventricular septal defect in two. We encountered the following secondary diseases: pulmonary stenosis in six patients, total atrioventricular septal defect in four, transposition of the great vessels in four, atrial isomerism in three, double outlet of the right ventricle in two, situs inversus totalis in one, dextrocardia in one and 'crisscross' heart in one.

The following procedures had previously been performed: the bi-directional Glenn operation in ten, BlalockTaussig-type systemic pulmonary connection in five and pulmonary branch banding in four giving a total of 19 previous operations.

The pre-operative hemodynamic data, as well as the Nakata index [6] of these patients are demonstrated in Table 1.

\section{Surgical Technique}

All the operations were performed by median sternotomy and under cardiopulmonary bypass at mild hypothermia and with the heart beating with the exception of two cases. In these cases the chosen surgery was to 
Table 1. Pre-operative data - 18 patients

\begin{tabular}{lcccc}
\hline & $\begin{array}{c}\text { RAP } \\
\text { mmHg }\end{array}$ & $\begin{array}{c}\text { PAP } \\
\text { mmHg }\end{array}$ & $\begin{array}{c}\text { DPLV } \\
\text { mmHg }\end{array}$ & N.I. \\
\hline $\mathrm{N}^{\mathrm{o}}$ patients & 16 & 15 & 14 & 17 \\
Variation & $3-12$ & $7-17$ & $5-14$ & $227-770$ \\
Mean & 8,3 & 12,5 & 8,8 & 395 \\
\hline
\end{tabular}

$\mathrm{RAP}$ - right atrium mean pressure; $\mathrm{PAP}$ - pulmonary artery mean pressure; DPLV - mean diastolic pressure of the left ventricle; N.I. - Nakata index.

utilize cold-blood cardioplegia. All the aorto-pulmonary shunts were divided and, in the absence of a previous bidirectional Glenn operation, the pulmonary branch, when present, was cross-sectioned and its distal stump sutured directly, to avoid distortion, where conditions can be ideal for the formation of thrombi [7]. The proximal stump of the pulmonary branch together with its valve was also sutured, but it was reinforced using Dacron, as the pressure at this stump is systemic and this technique averts bleeding at this site. The ligature of the pulmonary branch itself is not advisable, as the existence of orifices, which lead to residual shunts, is not uncommon.

In the absence of previous bi-directional Glenn operations, it was performed by the cross-sectioning of the superior vena cava, anastomosis of the cranial or distal stump on the superior face of the right pulmonary artery and closure of the atrial or proximal stump.

Following this, the inferior vena cava was clamped at the cavo-atrial junction and transectioned, closing its proximal portion with a double suture of monofilament thread. The distal or diaphragmatic stump was wound around the inferior vena cava cannula to arrest bleeding, and was anastomosed end-to-end to an expanded polytetrafluoroethylene tube (PTFE) of an adequate diameter using continuous suturing of monofilament thread. This tube was sectioned at the chosen length and its end anastomised to the inferior face of the right pulmonary artery using the same type of suturing. We prefer to anastomose the extracardiac conduit in this sequence, but evidently the sequence can be inverted depending on the preferences of the individual surgeon.

In this situation, the right atrium is totally isolated from the vena cavas and the interatrial connection (IAC) should be big enough to drain the venous blood in the left atrium if there is atresia of the tricuspid valve. If the IAC is small, it should be widened, which necessitates the opening of the cardiac chamber and the usual precautions to prevent accidents with gaseous emboli.

When the bi-directional Glenn operation precedes the cavopulmonary connection using an extracardiac conduit, intracardiac details such as the widening the IAC, the treatment of valve failure and other procedures, should be performed concurrently, to improve the evolution of the Glenn operation, which is the simplest operation. This should allow the second intervention to be performed without opening the heart chambers and therefore, without aortic ischemia or the use of cardioplegic solutions, guaranteeing by this better ventricular and pulmonary functioning.

The fortuitous fenestration between the extracardiac conduit and the remaining right atrium can be made at the end of the cardiopulmonary bypass perfusion or even after its termination. In general, a window is created with a diameter of four or five millimeters between the medial wall of the PTFE tube and the lateral wall of the atrium for cross-clamping. A short segment of PTFE tube with a diameter equal to the fenestration can also be used for the same purpose, or direct anastomosis can be performed between the extracardiac conduit and the right atrial appendix. In 12 of the 18 patients fenestration was not made. There was no difference in the evolution comparing the two groups.

The perfusion time varied from 60 to 150 minutes with a mean time of 89 minutes, depending on the existence or not of a previous bi-directional Glenn operation and on the necessity or not of interrupting the pulmonary branch. Opening of the chamber was necessary in only one of the 18 cases where, under protection of cardioplegia, the IAC was widened.

In all patients the post-operative rhythm was sinusal.

\section{RESULTS}

Three patients died in the immediate post-operative period giving a $16.6 \%$ hospital mortality rate. The first death occurred with a 12-year-old female patient diagnosed with a left univentricular atrioventricular connection associated with dextrocardia and transposition of the great vessels. Previously, she had been operated on to place a pulmonary branch band and consequently, to perform the bi-directional Glenn operation. She was operated on by the described method using a 20-mm Dacron tube impregnated with collagen (Hemashield), without fenestration. She evolved in the first 24 hours with progressively low output, low diuresis, acidosis, agitation and high venous pressure. She underwent a reoperation to perform the fenestration, when the presence of a thrombus in the extracardiac conduit was observed. As there was no improvement in her condition, she was once again taken to surgery and the conduit, which was by this time completely occluded, was removed. The left pulmonary artery that was anastomosed to the conduit was cleaned of thrombi using a Fogarty catheter, and a new 
conduit, this time of PTFE of the same caliber was employed. The patient remained unstable until the fifth post-operative day, when the pulmonary hemorrhagic state deteriorated and she died during a hemoptysis episode.

The second death was a 4-year-old female patient with diagnosis of grade $\mathrm{Ib}$ tricuspid atresia who had been previously submitted to a modified left Blalock-Taussig operation. The extracardiac conduit employed was a $20-\mathrm{mm}$ fenestrated corrugated bovine pericardium tube and death occurred on the second post-operative day due to progressive low cardiac output.

Finally, the third death happened with a 3-year-old female patient with left univentricular atrioventricular connection with an associated crisscross heart and pulmonary stenosis. Previously she had been submitted to the bi-directional Glenn operation. The extracardiac conduit utilized was a non-fenestrated 20-mm PTFE tube. Death occurred due to low heart output syndrome in the $24^{\text {th }}$ post-operative hour

Among the post-operative complications directly related to the extracardiac conduit which deserve specific attention was the occurrence of thrombosis, which included the normal type, with total occlusion of the tube or the slow, silent progressive layer form

There were four cases of thrombosis with one case evolving to death. All the four cases were submitted to reintervention. Apart from the case described above, a second case suffered from thrombosis and progressive calcification, which led to total occlusion of the conduit in a 5-year-old female patient who had right univentricular atrioventricular connection associated with total atrioventricular septal defect. This patient had undergone a previous banding of the pulmonary branch and a $21-\mathrm{mm}$ non-fenestrated pericardium tube was used. The reoperation occurred in the $15^{\text {th }}$ post-operative month with the patient complaining of tiredness and frequent sudoresis. The existing conduit was substituted for a non-fenestrated 20-mm PTFE tube under deep hypothermia and total cardiac arrest. The patient continues to evolve well.

The third patient was a 12-year-old male patient with diagnosis of grade $\mathrm{Ib}$ tricuspid atresia and who underwent a previous bi-directional Glenn operation. A 20-mm nonfenestrated PTFE tube was utilized. The post-operative evolution was complicated, with severe pericardial and pleural effusions, abundant protein loss and right phrenic paralysis, as well as chronically low heart output. The patient was re-operated on the $50^{\text {th }}$ post-operative day, when decortication of the right lung, folding of the right diaphragm and fenestration of the conduit and right atrium were performed. During the fenestration, laminar thrombus was diagnosed on the inside of the tube, but the patient was kept under observation with a great improvement in her clinical state, renal function, which was involved, anasarca and the protein loss. Magnetic resonance should have been used, which seems to be more useful to assess the dimensions of the conduit, the sites of anastomosis, the silent thrombosis and the formation of cellular hyperplasia on the inside of the conduit [8].

The last case involving thrombi in the extracardiac conduit was a 6-year-old male patient with diagnosis of grade Ib tricuspid atresia and previous bi-directional Glenn operation. In this case a $20-\mathrm{mm}$ non-fenestrated PTFE extracardiac conduit was employed and the patient evolved during 69 days with low cardiac output and high pressure in the pulmonary arteries. The option at that time was to reoperate to perform a 'takedown' during which, on opening the tube, a great amount of laminar thrombus was evidenced. The operation was changed to a bi-directional Glenn operation, with redirecting of the inferior vena cava to the right atrium. The post-operative evolution was excellent and the patient continues to be accompanied.

In the intensive care unit (ICU), the extubation time varied from 5 to 20 hours, where in $64 \%$ of the patients the time was less than 12 hours. The presence in some cases of bad ventricular function with low output, the tendency to acidosis and reduced diuresis maintained some patients in the ICU for a longer period of time, varying between 2 and 7 days. Even so, $71 \%$ of the cases were released by the fourth day. As all the patients were operated on by the same technique, without cardiac arrest, it was not possible to compare chance deleterious effects of both cardiac and pulmonary function.

In relation to fenestration, performed in only six patients, without any influence in the results, this allowed sufferers to have slightly less arterial saturation than the non-fenestrated patients. Confirmation of a reduction in the length of ICU stay or the thoracic drainage of these patients as has been reported in the literature [9] was not possible in our study, as has also been previously reported in other publications $[10,11]$. Thus, in this cohort, the mean thoracic drainage, during the first week, was $1,600 \mathrm{~mL}$ in the fenestrated patients and $1,890 \mathrm{~mL}$ in the non-fenestrated. During the second week, these values were 1,000 and $860 \mathrm{~mL}$ respectively. The duration of the thoracic drainage ranged from 11 to 90 days, with an average of 37 days in the fenestrated patients and 28 days in the non-fenestrated patients.

\section{COMMENTS}

After demonstrating the possibility of deviating the venous blood directly from the vena cavas to the lungs, as CARLON et al. [12] achieved experimentally and Meshalkin [13], GLENN [14] and others applied clinically, a series of modifications occurred. These passed the stage of atriopulmonary anastomosis as was described by KREUTZER 
et al. [15], SADE \& CASTANEDA [16] and others and in which the blood of the right atrium was conducted directly to the pulmonary artery system. It is interesting to remember here, that several of these techniques, including that of FONTAN \& BAUDET [1] introduced in the circuit, prostheses and even tubular conduits as in the operation of SADE \& CASTANEDO [16].

The subsequent evolution was the total cavopulmonary connection, thus avoiding stasis of the blood in the right atrium as seen in the atrio-pulmonary anastomosis or the turbulence seen in cases of atrio-ventriculo-arterial connections. And so, the hemodynamic concept of JONAS \& CASTANEDA [4] appeared that demonstrated the advantages of laminar flows, with less out flow and lower incidence of arrhythmia and of thrombi, introducing new courage in both patients and surgeons.

The circulatory system, after Fontan-type operations becomes, in a way, critical specifically in the post-operative period, when it is vulnerable to failure associated with progressive complications capable of making the whole surgery a failure. In this situation it is necessity to revert to procedures more compatible with survival, but without the advantages of being the first intervention.

Disorders of the ventricular or pulmonary function, the cardiac rhythm and the appearance of turbulence in the circuit, are the main causes of bad results.

The emergence of cavopulmonary connections with the construction of intra-atrial tunnels has given encouraging results $[8,17,18]$, but as yet not ideal. Since its introduction in 1990 by MARCELLETTI et al. [19], the cavopulmonary extracardiac connection utilizing a conduit is gradually becoming accepted as a new alternative for the surgical treatment of certain complex congenital heart diseases.

Among the advantages of the use of an extracardiac conduit is the possibility of employing it under normothermic cardiopulmonary bypass with a beating heart. This signifies it is not necessary to arrest the heart using cardioplegic solutions, which is important for the preservation of the ventricular and pulmonary function of these patients. The possibility of performing the procedure without the use of cardiopulmonary bypass is also recommended, thus giving the advantages of not using perfusion [20,21]. Nevertheless, for this to be possible, it is necessary not to open any heart chamber to effectuate parallel corrections, such as for example, to widen the restrictive interatrial connection, to correct valvar reflux, to amplify restrictive ventricular foramen ovale, etc. If it were necessary, the ideal choice would be to perform these procedures during the bi-directional Glenn operation, thus preparing the patient in this aspect for the second intervention. With these cares the systemic ventricular function, which is so important in the postoperative period, will be better preserved, as will the pulmonary function.

The disadvantage of not using perfusion is the difficulty of performing the procedure in virtue of chance events and damage to the pulmonary function during anastomosis due to tangential clamping of the pulmonary arteries. Also there is a possibility of increasing the intrahepatic venous pressure owing to bad drainage of the intra-hepatic vein cannula diverting the blood to the right atrium [10].

Another advantage of the extracardiac conduit is the lower incidence of arrhythmias, because fewer sutures in the right atrium, especially in the septal region and near to the sinusal node, are required, as well as the lower pressure in this chamber which is isolated from the venous circuit.

The tendency to fenestrate the anastomosis diminishes in relation to other techniques by improving the conditions immediately after the operation. Also, if it is necessary, fenestration can be performed between the conduit and the right atrium without the necessity of perfusion in a simpler and more benign procedure. Fenestration has been used only on patients in whom there was evidence of marginal hemodynamic conditions in the post-perfusion period. In this cohort, six patients were fenestrated against 12 who were not, thus avoiding desaturation and systemic embolization, as well as the necessity in the future of additional procedures to close the fenestration, even though it is known that $30 \%$ close spontaneously.

The utilization of extracardiac conduit in total cavopulmonary connection, however, is not always advantageous and among the complications that may arise are thrombogenicity, the formation of cellular hyperplasia, fibrosis and calcification and the absence of growth. All are severe complications, which can occur in the immediate postoperative period or even months or years after the intervention and shadow the late evolution.

The Fontan operation in its varying ways of being performed was always associated with approximately $20 \%$ of thromboembolism in the post-operative period [22]. Owing to this, the patients in this study to be routinely prescribed Warfarin sodium, using salicylic acetyl acid only when the use of the former was impossible or after the 12 postoperative month for the rest of their lives. This, however, did not avoid the occurrence of thrombi in the conduit, with initiation within 24 hours in one of the patients and with total occlusion of the tube, which forced replacement but this did not impede a lethal result of the complication.

Another case related to fibrosis, calcification and total thrombosis of the conduit with a slower evolution, led to replacement of the tube 15 months after surgery, with a good result. Still within the same thrombotic complications, another two cases with the silent form of laminar thrombosis led the sufferers to a progressive deterioration of the initially good result, possible due to repetitive pulmonary 
embolization and an increase in the venous pressure, with thoracic stroke and chronic protein loss. One of them was treated on the $50^{\text {th }}$ post-operative day using fenestration performed without cardiopulmonary bypass, with obvious improvement but without it being the ideal solution. The other was treated with 'takedown', converting to the bidirectional Glenn procedure and, thus, representing a return to the ideal conduct.

In this experience, still preliminary, we used, especially at the start, conduits of different materials such as bovine pericardium in four cases, the Hamashield in another four and PTFE in the other ten cases. Thrombosis occurred in one case in each of the first two materials and two cases with PTFE, showing in this cohort the absence of an association between them. We do not have experience of the pedicled pericardium of the patients themselves [23], aortic homograft [10] or tissue produced by bioengineering [24].

The comment by JONAS [25] is interesting, when he reports on the publication by FONTAN et al. [26] in the review of surviving patients and where the majority of the morbidity was associated to the use of conduit, that was frequently used at that time. Are we now, despite of the conduit being a different material and in another position, repeating the same errors? What has the luck been, over a long term, of the most varied conduits used in the reconstruction of the rightventricular outlet tract [27]?

The occurrence of both normal or laminar thrombosis seems to be related to several causes, among which the presence of foreign bodies and protein material within the heart which might act as a site for the formation of thrombi. This is in agreement with the echocardiographic findings of thrombi formed on the venous side and adherents to the flap of foreign material utilized in the separation of the systemic from the pulmonary blood [28]. The association of this fact with the tendency of reduced flow speed on the venous side and the almost certainty that formation of the endothelium will not occur along all the conduit used, are factors which can result in an increase in the frequency of thrombi. In this work the facts seem to point in this direction, with an incidence of $22.2 \%$ even with the careful use of oral anticoagulation.

The presence of cellular hyperplasia on the inside of the conduits and the development of fibrosis and progressive calcification are well known and only add to the previous concern [29].

Finally, the characteristic that the conduits do not change still remains, which is the absence of growth. This makes several authors [9,10-21] recommend the use of conduits that might be compatible with the lives of adults (diameters of 20 to $22 \mathrm{~mm}$ ) and that should be utilized in over 3-and 4-year-old patients with a weight of more than $15 \mathrm{~kg}$. The utilization of oversized conduits in young patients, as an attempt of adapting the diameter to a longer evolution, does not seem to be the best choice as this might induce a greater tendency for the formation of laminar thrombosis.

In conclusion, this initial experience shows that cavopulmonary connection with extracardiac conduit can be safely performed, using normothermic perfusion, with the heart beating, without cardioplegia and with a good ventricular preservation. Additionally, fenestration can be used with more restraint and, if necessary, performed afterwards in a simple surgery in the postoperative period. However, a long careful assessment of its advantages is necessary, especially those related to a better quality of life over the long term, without complications such as arrhythmias, thromboembolic events, permanent medication, and the necessity of re-interventions, which do not seem to occur with the use of extracardiac conduits. We should take care, in our enthusiasm, not to create today, the patients of tomorrow.

\section{BIBLIOGRAPHIC REFERENCES}

Fontan F, Baudet E. Surgical repair of tricuspid atresia. Thorax $1971 ; 26: 240-8$.

2. Kawashima Y, Kitamura S, Matsuda H, Shimazaki Y, Nakano $\mathrm{S}$, Hirose H. Total cavopulmonary shunt operation in complex cardiac anomalies: a new operation. J Thorac Cardiovasc Surg 1984; 87:74-81.

3. Puga FJ, Chiavarelli M, Hagler DJ. Modifications of the Fontan operation applicable to patients with left atrioventricular valve atresia or single atrioventricular valve. Circulation 1987; 76 III 53-60.

4. Jonas RA, Castaneda AR. Modified Fontan procedure: atrial baffle and systemic venous to pulmonary artery anastomotic techniques. J Card Surg 1988; 3:91-6.

5. De Leval MR, Kilner P, Gewillig M, Bull C. Total cavopulmonary connection: a logical alternative to atriopulmonary connection for complex Fontan operations. Experimental studies and early clinical experience. J Thorac Cardiovasc Surg 1988; 96:682-95.

6. Nakata S, Imai Y, Takanashi Y, Kurosawa H, Tezuka K, Nakazawa $\mathrm{M}$ et al. A new method for the quantitative standardization of cross-sectional areas of the pulmonary arteries in congenital heart diseases with decreased pulmonary blood flow. J Thorac Cardiovasc Surg 1984; 88: 610-9.

7. Rosenthal DN, Bulbul ZR, Friedman AH, Hellenbrand WE, Kleinman CS. Trombosis of the pulmonary artery stump after distal ligation. J Thorac Cardiovasc Surg 1995; 110: 1563-5.

8. Giannico S, Corno A, Marino B, Cicini MP, Gagliardi MG, Amodeo A et al. Total extracardiac right heart bypass. Circulation 1992; 86:II 110-7. 
9. Alexi-Meskishvili V, Ovroutski S, Dähnert I, Lange PE, Hetzer R. Early experience with extracardiac Fontan operation. Ann Thorac Surg 2001; 71:71-7.

10. Azakie A, McCrindle BW, van Arsdell G, Benson LN, Coles J, Hamilton R et al. Extracardiac conduit versus lateral tunnel cavopulmonary connections at a single institution: impact on outcomes. J Thorac Cardiovasc Surg 2001; 122: 1219-28.

11. Lemler MS, Scott WA, Leonard SR, Stromberg D, Ramaciotti C. Fenestration improves clinical outcome of the Fontan procedure: a prospective, randomized study. Circulation 2002; 105:207-12.

12. Carlon CA, Mondini PG, De Marchi R. Surgical treatment of some cardiovascular diseases (a new vascular anastomosis). J Int Coll Surg 1951; 16:1-10.

13. Meshalkin EN. Anastomosis of the superior vena cava with the pulmonary artery in patients with congenital heart disease with blood flow insufficiency in the lesser circulation: experiment. Eksp Khir 1956; 6:3-12.

14. Glenn WWL. Circulatory bypass of the right side of the heart: shunt between superior vena cava and distal right pulmonary artery. Report of clinical application. N Engl J Med 1958; 259:117-20.

15. Kreutzer G, Galindez E, Bono H, De Palma C, Laura JP. An operation for the correction of tricuspid atresia. J Thorac Cardiovasc Surg 1973; 66:613-21.

16.Sade RM, Castaneda AR. The dispensable right ventricle. Surgery $1975 ; 77: 624-31$.

17. Leval MR, Kilner P, Gewillig M, Bull C. Total cavopulmonary connection: a logical alternative to atriopulmonary connection for complex Fontan operation: experimental studies and early clinical experience. J Thorac Cardiovasc Surg 1988; 96:682-95.

18. Cetta F, Feldt RH, O'Leary PW, Mair DD, Wames CA, Driscoll DJ et al. Improved early morbidity and mortality after Fontan operation: the Mayo Clinic experience, 1987 to 1992. J Am Coll Cardiol 1996; 28:480-6.
19. Marcelletti C, Corno A, Giannico S, Marino B. Inferior vena cava-pulmonary artery extracardiac conduit: a new form of right heart bypass. J Thorac Cardiovasc Surg 1990; 100:228-32.

20. Burke RP, Jacobs JP, Ashraf MH, Aldousany A, Chang AC Extracardiac Fontan operation without cardiopulmonary bypass. Ann Thorac Surg 1997; 63:1175-7.

21. McElhinney DB, Petrossian E, Reddy VM, Hanley FL. Extracardiac conduit Fontan procedure without cardiopulmonary bypass. Ann Thorac Surg 1998; 66:1826-8.

22. Rosenthal DN, Friedman AH, Kleinman CS, Kopf GS, Rosenfeld LE, Hellenbrand WE. Thromboembolic complications after Fontan operations. Circulation 1995; 92: II 287-93.

23. Gundry SR, Razzouk AJ, Del Rio MJ, Shirali G, Bailey LL. The optimal Fontan connection: a growing extracardiac latera tunnel with pedicled pericardium. J Thorac Cardiovasc Surg 1997; 114:552-9.

24. Naito Y, Imai Y, Shin'oka T, Kashiwagi J, Aoki M, Watanabe $\mathrm{M}$ et al. Successful clinical application of tissue-engineered graft for extracardiac Fontan operation. J Thorac Cardiovasc Surg 2003;125:419-20.

25. Jonas AR. Commentary. J Thorac Cardiovasc Surg 1999; 695-6.

26. Fontan F, Kirklin JW, Fernandez G, Costa F, Naftel DC, Tritto $F$ et al. Outcome after a "perfect" Fontan operation. Circulation $1990 ; 81: 1520-36$

27. Wells WJ, Arroyo Jr. H, Bremner RM, Wood J, Starnes VA. Homograft conduit failure in infants is not due to somatic outgrowth. J Thorac Cardiovasc Surg 2002; 124:88-96.

28. Coon PD, Rychik J, Novello RT, Ro PS, Gaynor JW, Spray TL. Thrombus formation after the Fontan operation. Ann Thorac Surg 2001; 71: 1990-4.

29. Amodeo A, Galletti L, Marianeschi S, Picardo S, Giannico S, DiRenzi P et al. Extracardiac Fontan operation for complex cardiac anomalies: seven years experience. J Thorac Cardiovasc Surg 1997;114:1020-31. 